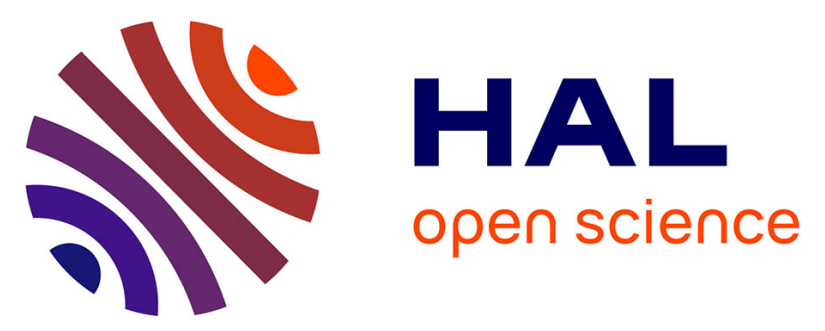

\title{
Performances of Magneto-Electric Dipoles in an Antennas Array with a Reduced Beam Forming Network
}

Abdul-Sattar Kaddour, Jorick Milbrandt, Cyrille Menudier, Marc Thevenot, Philippe Pouliguen, Patrick Potier, Maxime Romier

\section{- To cite this version:}

Abdul-Sattar Kaddour, Jorick Milbrandt, Cyrille Menudier, Marc Thevenot, Philippe Pouliguen, et al.. Performances of Magneto-Electric Dipoles in an Antennas Array with a Reduced Beam Forming Network. 2019 16th European Radar Conference (EuRAD), Oct 2019, Paris, France. 10.23919/EuMC.2019.8910690 . hal-02402089

\section{HAL Id: hal-02402089 \\ https://hal.science/hal-02402089}

Submitted on 3 Dec 2020

HAL is a multi-disciplinary open access archive for the deposit and dissemination of scientific research documents, whether they are published or not. The documents may come from teaching and research institutions in France or abroad, or from public or private research centers.
L'archive ouverte pluridisciplinaire HAL, est destinée au dépôt et à la diffusion de documents scientifiques de niveau recherche, publiés ou non, émanant des établissements d'enseignement et de recherche français ou étrangers, des laboratoires publics ou privés. 


\title{
Performances of Magneto-Electric Dipoles in an Antennas Array with a Reduced Beam Forming Network
}

\author{
Abdul-Sattar Kaddour ${ }^{1}$, Jorick Milbrandt ${ }^{1}$, Cyrille Menudier ${ }^{1}$, Marc Thévenot ${ }^{1}$, Philippe Pouliguen ${ }^{2}$, Patrick Potier ${ }^{2}$, \\ Maxime Romier ${ }^{3}$ \\ ${ }^{1}$ Univ. Limoges, XLIM, UMR 7252, F-87000 Limoges, France, cyrille.menudier@xlim.fr \\ ${ }^{2}$ DGA, Direction Générale de l'Armement, France \\ ${ }^{3}$ CNES, Centre National d'Etudes Spatiales, Toulouse, France
}

\begin{abstract}
In this paper, we propose an architecture of array based on parasitic element antennas with multiple excitations. The objective is to improve the directivity of these antenna arrays using Magneto-Electric Dipoles (MED). In this contribution, we consider a $49(7 \times 7)$ element array with only $8 \%$ of the elements directly fed. The others are fed by couplings and they are loaded on reactive values (ideally). The proposed radiating element is compared to a stacked patch design in the same reduced feed network configuration. A maximum directivity of $20 \mathrm{dBi}$ is obtained, allowing several reconfigurable antenna scenarios based on such as design.
\end{abstract}

Keywords - antenna array, parasitic element antenna, reconfigurable antenna, magneto-electric dipole.

\section{INTRODUCTION}

Electronic beam steering or beam forming capabilities are very attractive for many applications such as satellite communications, wireless networks and automotive radars. In this context, phased-arrays antennas [1] are considered as good candidates due to their attractive features in terms of performances, several degrees of freedom and complex beamforming possibilities. Nevertheless, in some cases they suffer from very complex and expensive feed network. Because of their cost, they are often limited to spatial missions or military applications. To overcome these limitations, a hybrid antenna array is proposed in [2] derived from the original one from Harrington [3] and is depicted in Fig. 1. This solution is considered as a crossover between lacunar arrays and parasitic element antennas. A reduced number of elements are fed directly with RF chains, in order to spread the couplings on the lattice surface. These couplings are used to feed radiating elements (parasitic ones) not connected to the feed distribution network. Each of them is connected to a reflection-type phase shifter (RTPS) in order to manage their contribution to the radiated electromagnetic field. They are considered as degrees of freedom to optimize the overall performance of the system. The obtained directivity is only decreased by $1.2 \mathrm{~dB}$ whereas only $15 \%$ of the elements are directly excited in the lattice, in the ideal case of no insertion losses for RTPS.

From the classical antenna array theory [4], the amount of directivity is generally related to several factors such as the directivity of the radiating elements, the number of elements and the level of coupled energy into adjacent parasitic elements when dealing with parasitic arrays. However, when a classical wideband stacked patch antenna is used as radiating element, the coupled energy in the $\mathbf{E}$ Plane and $\mathbf{H}$ Plane are not equal. Hence, the need to use radiating elements which can achieve homogenous coupling between $\mathbf{E}$ and $\mathbf{H}$ plane is an important improvement to enhance overall performances.

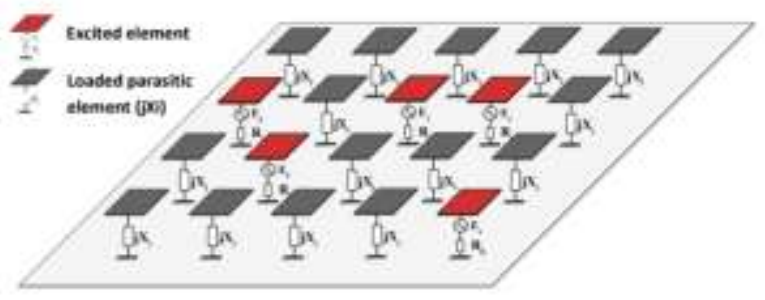

Fig. 1. Principle of hybrid array

A detailed state of art shows that "Magneto Electric" dipole antennas proposed in [5] are promising solutions with excellent radiation characteristics and wide impedance matching. These antennas are based on the concept of the Huygens source [5] with very interesting characteristics such as identical radiation pattern and very low back lobe radiation, both in the $\mathbf{E}$ and $\mathbf{H}$ planes.

In this paper, we present a reduced BFN parasitic array using magneto-electric elements to improve the antenna directivity. The paper is organized as follows. The magnetoelectric dipole is presented in Section II. Here, its principal operation and performances are presented. The magnetoelectric dipole is then used to form $7 \mathrm{X} 7$ reduced BFN array to achieve a reconfigurable radiation beam. The structure of the array and its operation principle is presented in Section III. The array has been simulated and directional radiation beams were synthesized. The obtained results are presented in Section IV. Concluding remarks are presented in Section V.

\section{Magneto-Electric Dipole}

\section{A. Antenna element description}

The Magneto-Electric dipole (MED) antenna used in this paper was developed in [5] and presented in Fig. 2. The 
Antenna consists on combining an electric dipole antenna with a magnetic dipole antenna. The electric dipole is made from two planar rectangular metal sheets; while the magnetic dipole is made from a wideband short-circuited patch. The shortcircuited patch is placed vertically and is connected to the planar electric dipole. To excite the antenna, an $\Gamma$-shaped probe feed is employed. This feed consists of three portions, which is made by folding a straight metallic strip of rectangular crosssection into a $\Gamma$-shape. The antenna dimensions are presented in Table 1.
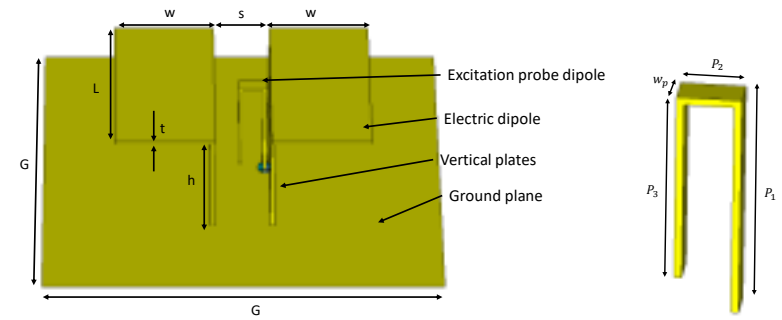

(a)

(b)

Fig. 2. (a) Magneto-electric antenna (b) Excitation probe.

Table 1. Antenna Dimensions.

\begin{tabular}{|c|c|c|c|c|c|}
\hline Parameters & $\boldsymbol{G}$ & $\boldsymbol{L}$ & $\boldsymbol{W}$ & $\boldsymbol{H}$ & $\boldsymbol{S}$ \\
\hline Dimenions (mm) & 120 & 60 & 30 & 31 & 17 \\
\hline Parameters & $\boldsymbol{t}$ & $\boldsymbol{P}_{\boldsymbol{1}}$ & $\boldsymbol{P}_{\boldsymbol{2}}$ & $\boldsymbol{P}_{\mathbf{3}}$ & $\boldsymbol{W}_{\boldsymbol{p}}$ \\
\hline Dimenions (mm) & 1 & 30 & 8.5 & 26.5 & 2.91 \\
\hline
\end{tabular}

\section{B. Operation Principle}

In this section, the operating principle of the magnetoelectric dipole is discussed. This basic design of the magnetoelectric dipole is composed of a vertically oriented quarterwave shorted patch antenna and a planar electric dipole, which is equivalent to a combination of a magnetic dipole and an electric dipole to form a radiating element.

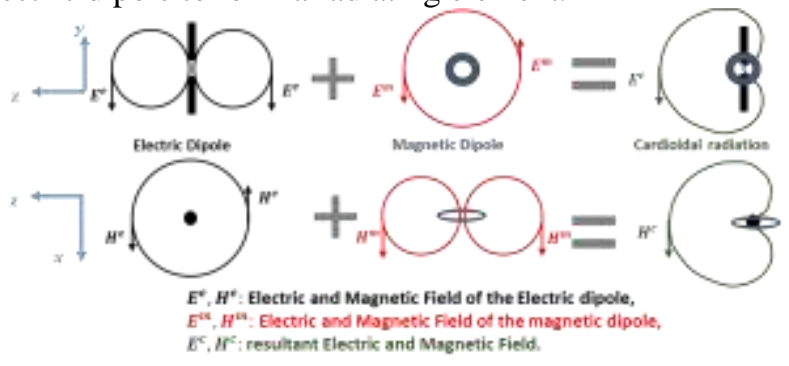

Fig. 3. (a) Radiation pattern of the combination of an electric dipole and a magnetic dipole.

The radiation pattern due to the combination of an electric dipole and a magnetic dipole is shown in Fig. 3. Two radiating sources are placed perpendicularly to each other to radiate in a complementary manner. Black and red lines describe the field patterns of the electric and the magnetic dipoles, respectively. The electric dipole radiates uniformly in the $\mathbf{H}$ plane, whereas the magnetic dipole radiates bi-directionally in the $\mathrm{H}$ plane. In the $\mathbf{E}$ plane, the electric dipole radiates bidirectionally, whereas the magnetic dipole radiates uniformly in the $\mathbf{E}$ plane. When the electric and magnetic dipoles are excited simultaneously with proper amplitudes and phases, a circularly symmetric cardioidshaped radiation pattern with very low back lobe radiation, both in the $\mathbf{E}$ and $\mathbf{H}$ planes, can be achieved. The Huygens source's concept of a magneto electric type antenna was demonstrated in [6] using spherical wave expansion analysis; the antenna presents the same behavior as a generalized Huygens source with identical contribution of transverse electric (TE) and transverse magnetic (TM) modes over a wide bandwidth.

\section{Operation Principle}

The simulated VSWR and realized gain at $\left(\theta=0^{\circ}, \varphi=0^{\circ}\right)$ of the Magneto-electric dipole antenna is depicted in Fig. 4. The antenna operates from 1.79 to $2.57 \mathrm{GHz}$ with a bandwidth of $36 \%(\mathrm{VSWR}<2)$. The broadside gain at $\left(\theta=0^{\circ}\right)$ is $7.65 \pm .0 .15 \mathrm{dBi}$ over the operation band. These results show a stable radiation pattern over the operation bandwidth.

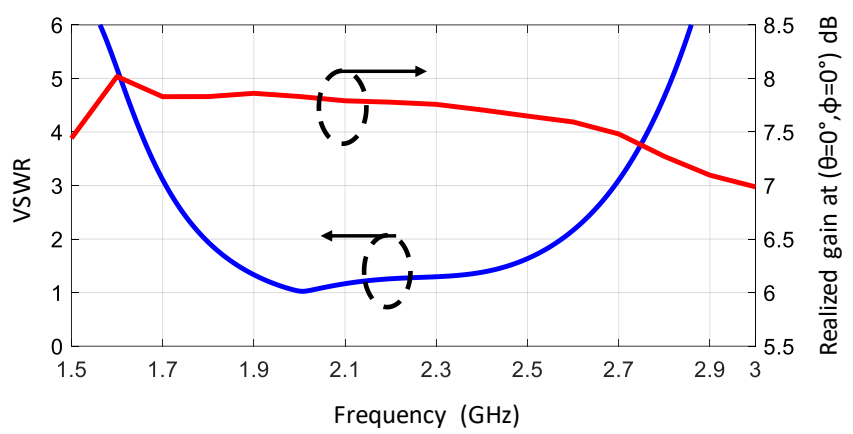

Fig. 4. VSWR and Realized gain at $\left(\theta=0^{\circ}, \varphi^{\circ}=0^{\circ}\right)$ versus frequency.

\section{RADIATION PANEL}

This section describes the design and analysis of the radiating panel of 49 (7-by-7) radiating elements. The design of the proposed antenna is shown in Fig. 5. The radiation panel is composed of 49 Magneto-electric dipoles with a half wavelength (at $1.9 \mathrm{GHz}$ ) spacing to maintain a high level of mutual couplings.

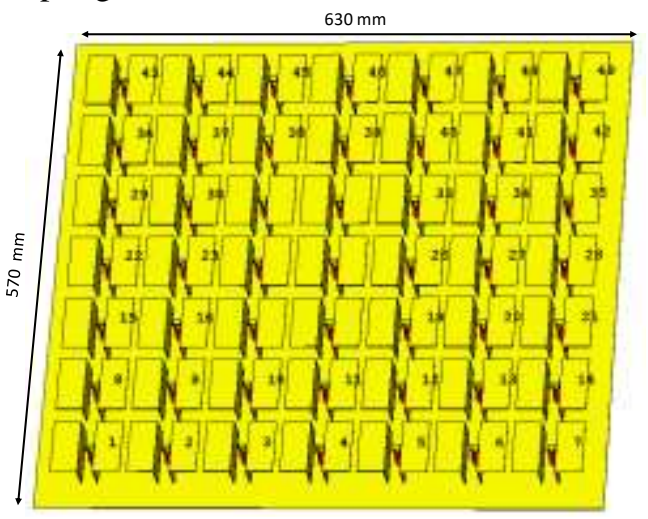

Fig. 5. Geometry of Magento-Electric dipoles array with 7 X 7 Elements.

\section{A. Characteristics of the $7 \times 7$ Array Elements}

Before using the lattice as a reduced BFN array, the main characteristics of the panel are studied. The simulated $\mathrm{S}$ 
parameters when central (red curve) and edge (blue curve) elements are excited are shown in Fig. 6. The proposed antenna offers a $36 \%$ bandwidth from 1.8 to $2.59 \mathrm{GHz}$. The mutual couplings between the cells are shown in Fig. 7. The couplings between two adjacent cells are above $-16 \mathrm{~dB}$ on a wide bandwidth in both $\mathbf{E}$ plane and $\mathbf{H}$ plane. For example, at $1.9 \mathrm{GHz}$ the coupling is $-12 \mathrm{~dB}$ and $-15 \mathrm{~dB}$ in both $\mathbf{E}$ plane and $\mathbf{H}$ plane, respectively.

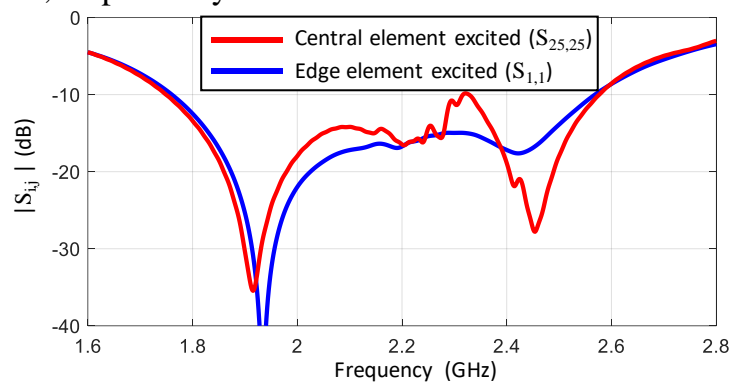

Fig. 6. Simulated reflection coefficient of the proposed design.

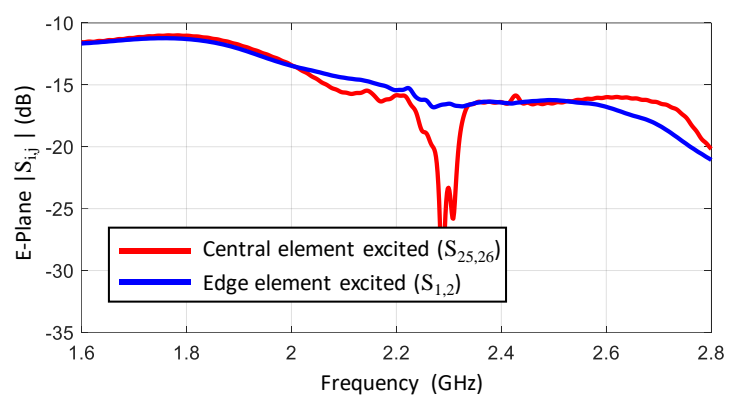

(a)

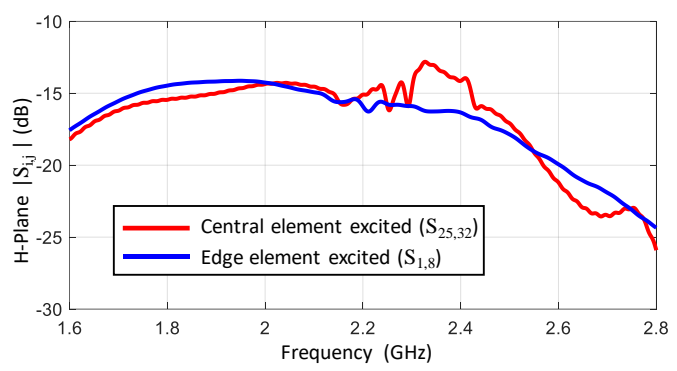

(b)

Fig. 7. Mutual coupling between two adjacent cells in the (a) E Plane and (b) H plane.

\section{REDUCED BFN ARRAY PERFORMANCES}

The proposed antenna has a behaviour strongly defined by mutual couplings. A synthesis process based on [7] is used to define the phase shifts required for each RTPS, provided a set of objectives in terms of gain and directions, and constraints on the active VSWR. The number and locations of excited elements is defined by the user. We have synthesized the array configuration based on the 7 X 7 Magneto-Electric dipole lattice. The radiation objective has been set to tilt in the direction $\left\{\theta_{0}=30^{\circ}, \varphi_{0}=30^{\circ}\right\}$. In this configuration, a constraint on the antenna active matching has been set below $-10 \mathrm{~dB}$ from 1.8 to $2.2 \mathrm{GHz}$. The hybrid array configuration is shown in Fig.8. It is composed of 4 excited elements among 49, other ones are considered as parasitic with RTPS. Red squares correspond to excited elements and grey squares to those excited by mutual couplings.

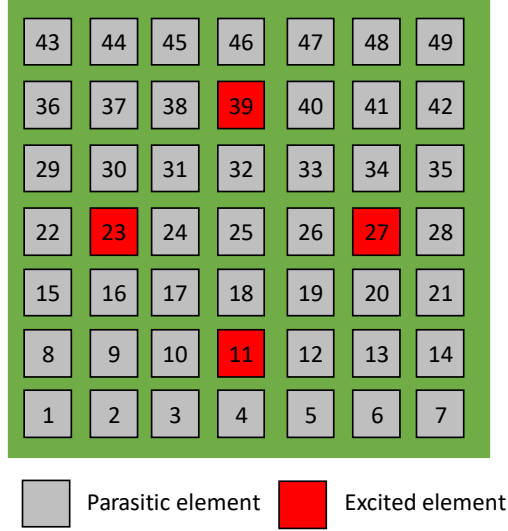

Fig. 8. Hybrid antenna array $7 \times 7$ with only 4 elements excited.

\section{A. Synthesis results}

The resulting radiation pattern and reflection coefficients for all the RF excited ports are given on Fig. 9 and Fig. 10, respectively. The obtained directivity is $18.3 \mathrm{dBi}$ and all the excited ports are matched over the desired frequency bandwidth. According to Fig. 11, couplings are well spread and we note that almost all ports contribute to the radiation.

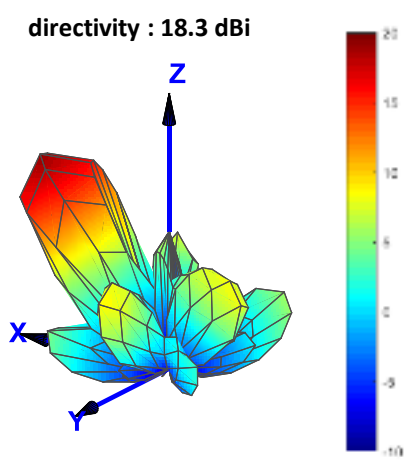

Fig. 9. Radiation pattern for an objective beam steering in the direction $\left\{\theta_{0}=30^{\circ}, \varphi_{0}=30^{\circ}\right\}$.

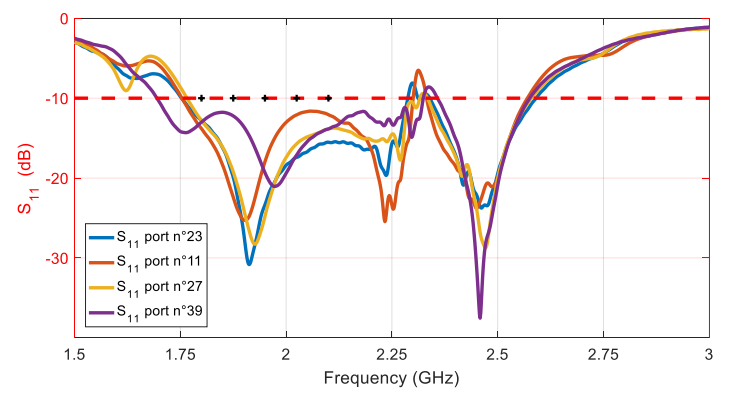

Fig. 10. Active reflection coefficient for excited ports 11, 23, 27 and 39. 


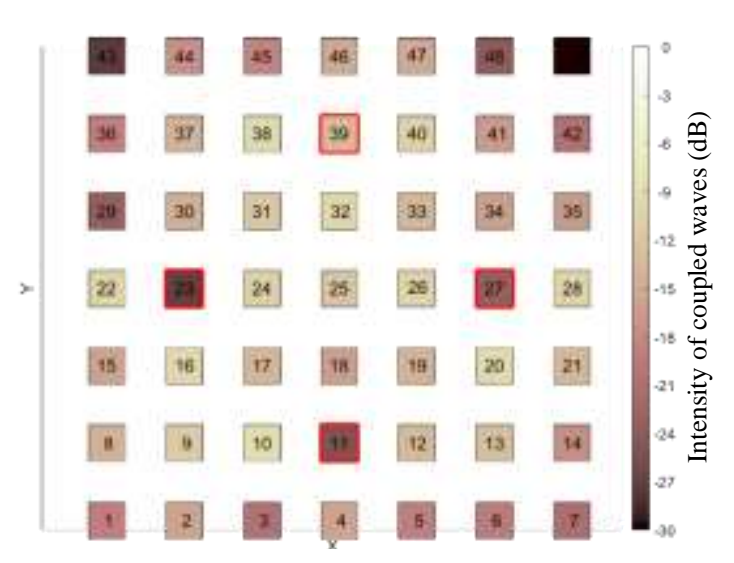

Fig. 11. Cartography of the intensity of coupled waves.

A. Synthesis results for different beam steering and comparison to a patch unit cell

The synthesized directivity for different radiation pattern direction objectives: $\left\{0^{\circ}<\theta_{0}<60^{\circ}\right.$ with $\left.\Delta \theta=10^{\circ}\right\}$ and $\left\{0^{\circ}<\varphi_{0}<90^{\circ}\right.$ with $\left.\Delta \varphi=10^{\circ}\right\}$ of the reduced BFN array with MED and classical patch antenna [4] are presented in Fig. 12a and Fig. $12 \mathrm{~b}$ respectively. For a fair comparison, the optimization was made on a bandwidth of $15 \%$ for both arrays (because a clear advantage of MED is the frequency band behaviour). The directivity using magneto-electric dipole is typically $2 \mathrm{dBi}$ higher than the classical stacked patch antenna. This is explained by the presence of higher coupling in both $\mathbf{E}$ and $\mathbf{H}$ planes and higher gain of the unit cell compared to the patch array antenna. The maximum attainable directivity is in the broadside direction $\left(\theta=0^{\circ}\right)$ and is equal to $20 \mathrm{dBi}$.

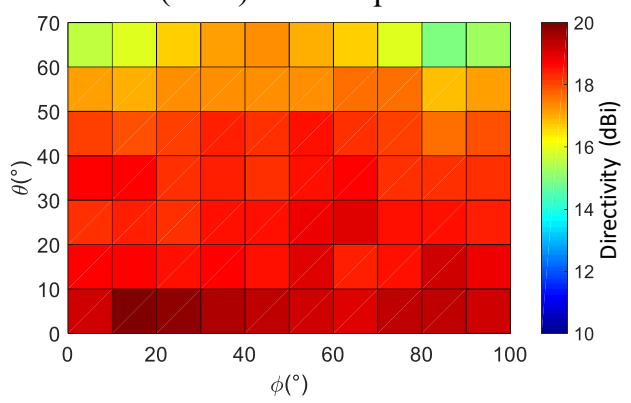

(a)

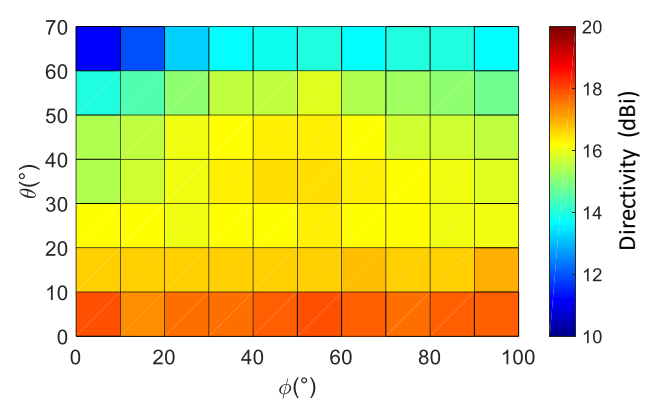

(b)

Fig. 12. Directivity as function of the beam steering direction for the reduced BFN antenna: (a) MED antenna, (b) patch antenna.

\section{CONCLUSION}

In this paper, an interesting concept of array with parasitic element antennas and multi-excitation has been proposed and its performances have been estimated. The proposed antenna array is composed of 49 Magneto-electrical dipoles. Due to their Huygens' source principle, magneto-electric antennas have almost equal and stable $\mathbf{E}$ and $\mathbf{H}$ plane radiation over wideband operation frequency compared to classical patch antennas. The maximum obtained directivity is $20.6 \mathrm{dBi}$ compared to $17.5 \mathrm{dBi}$ in the same reduced $\mathrm{BFN}$ array with microstrip patches. Future works to realize a demonstrator are currently being led.

\section{ACKNOWLEDGMENT}

The authors would like to thank ANR and DGA "Direction Générale de l'Armement", in France, for funding this work through the ANR ASTRID program $\mathrm{NA}^{2} \mathrm{~S}^{2} \mathrm{~A}$ "Novel Antenna Architectures with a Simplified Feeding Network".

\section{REFERENCES}

[1] C. A. Balanis, "Antenna Theory Analysis and Design", John Wiley \& Sons Editions, 2005.

[2] A. Oueslati, C. Menudier, M. Thevenot and T. Monediere, "Potentialities of hybrid arrays with parasitic elements," The 8th European Conference on Antennas and Propagation (EuCAP 2014), The Hague, 2014, pp. $1829-1830$.

[3] R. F. Harrington and J. R. Mautz, "Pattern synthesis for loaded Nport scatterers," IEEE Trans. Antennas Propag., vol. 22, no. 2, pp. 184-190, Mar. 1974

[4] H. Elzein, C. Menudier, M. Thevenot and T. Monediere, " Optimization of the VSWR of reconfigurable antennas with a coupled multielement concept," The 12th European Conference on Antennas and Propagation (EuCAP 2018), London, 2014, pp. 1829-1830.

[5] K. M. Luk and H. Wong, "A new wideband unidirectional antenna element," Int. J. Microw. Opt. Technol., vol. 1, no. 1, pp. 35-44, Jun. 2006.

[6] A. S. Kaddour, S. Bories, A. Clemente, A. Bellion and C. Delaveaud, "Radiation modes investigation of Huygens source type antenna using spherical wave expansion," in Proc. IEEE Int. Symp. Antennas Propag. (ISAP), Okinawa, Japan, Oct. 2016, pp. 664-665.

[7] M. Thevenot, C. Menudier, A. El Sayed Ahmad, G. Zakka El Nashef, F. Fezai, Y. Abdallah, E. Arnaud, F. Torres, and T. Monediere, "Synthesis of Antenna Arrays and Parasitic Antenna Arrays with Mutual Couplings," Int. J. Antennas Propag., vol. 2012, p. e309728, Apr. 2012. 